\title{
O ESTILO DE VICTOR BURTON: um olhar sobre o design do livro iconográfico brasileiro
}

\author{
Carolina Noury Azevedo \\ Universidade do Estado do Rio de Janeiro, ESDI/UERJ \\ carolinanoury@gmail.com \\ Guilherme Cunha Lima \\ Universidade do Estado do Rio de Janeiro, ESDI/UERJ \\ gecunhalima@globo.com
}

\begin{abstract}
Resumo: O designer Victor Burton começou a atuar no mercado editorial brasileiro em 1977 quando foi convidado pelo editor Carlos Lacerda, da Nova Fronteira, a trabalhar no seu novo projeto, a Confraria dos Amigos do Livro, uma editora especializada em livros de arte. Entretanto, com a morte precoce de Lacerda, o projeto não teve continuidade e Victor Burton passou a trabalhar como designer exclusivo da editora Nova Fronteira. Em 1986, após um convite de Luiz Schwarcz, editor da Companhia das Letras, Victor Burton começou a trabalhar para diversas editoras assumindo cada vez mais o projeto gráfico do livro, sobretudo o iconográfico, criando um estilo próprio em que é possível identificar a autoria dos seus livros. Sendo assim, através da trajetória do designer Victor Burton buscamos resgatar e construir um pedaço da memória do design editorial brasileiro e ainda identificar os elementos presentes característicos do seu estilo que nos permite identificar a autoria do seu projeto gráfico.
\end{abstract}

Palavras-chave: História do design brasileiro, Design editorial, Livro iconográfico, design gráfico.

\begin{abstract}
The designer Victor Burton began to act at the brazilian editorial market at 1977 when he was invited by Carlos Lacerda to work in his new project, the Confraria dos Amigos do Livro. Part of the Nova Fronteira publishing house, the Confraria should be responsable to edit arts books. However, due the Lacerda's early death in that same year, the project was put aside, and Victor Burton started to work for Nova Fronteira, where he had been an exclusive designer for six years. In 1986, Luiz Schwarcz invited Victor Burton to work at Companhia das Letras and from that moment on, Victor assumed more and more graphical projects of Brazilian books, especially the iconographic books. Thus, through the trajectory of designer Victor Burton we seek to rescue a piece of the Brazilian editorial design memory, and identify the elements characteristic of his style that allows us to identify the authorship of his graphic design.
\end{abstract}


Keywords: History of the Brazilian design, Editorial design, Iconographic book, Graphic Design.

\section{INTRODUÇÃO}

Ao longo da história do design editorial brasileiro, a preocupação com o projeto gráfico do livro e com a construção de uma identidade visual nem sempre foi uma constante entre os editores. Podemos dizer que somente a partir do início do século $\mathrm{XX}$, o mercado livreiro passou por uma revolução estética trazendo uma qualidade gráfica e visual a este produto. Diversos foram os editores e designers responsáveis pela consolidação do projeto gráfico do livro brasileiro, sendo um deles Victor Burton.

Nascido em 1956 na cidade do Rio de Janeiro, Victor se mudou com a família para Milão aos 7 anos de idade, devido à instabilidade política do Brasil que vivia um período incerto pré golpe militar. Filho do francês Michel Burton, designer formado pela escola de Arts and Métiers de Genebra e diretor de arte da revista Senhor nos anos 1960, Victor quis se tornar designer para fazer livros. Apesar de nunca ter trabalhado ao lado do pai, o convívio com Michel foi uma forte referência para o trabalho de Victor.

A família Burton é uma família de bibliófilos. Esse hobby começou com o bisavô de Victor que tinha uma pequena coleção de livros, e que o avô, Henry Burton, deu continuidade e investiu no acervo da coleção chegando a fazer parte de um desses seletos grupos de colecionadores. $O$ irmão de Henry, tio-avô de Victor, também era bibliófilo e parte da sua coleção está, hoje, no museu de Genebra. O contato com um rico acervo de livros raros, de edições especiais e livres d'artiste, despertou o interesse de Victor pelo livro e foi uma forte referência para o seu trabalho.

Seus primeiros trabalhos no campo do design editorial se deram ainda na Itália, aos 17 anos, na editora /I Formichiere e logo em seguida começou um estágio ao lado de Franco Maria Ricci, uma editora especializada em livros de arte. A formação de Victor se deu de maneira informal, no convívio com o pai e durante o período de um ano e meio em que trabalhou com Ricci, o que lhe garantiu o aprendizado das técnicas e da prática do design editorial. $\mathrm{O}$ ambiente cultural em que estava inserido funcionou como uma mola propulsora da produção de Victor Burton.

Como o principal interesse de Victor no livro é a relação entre texto e imagem, ao longo do seu trabalho ele passou a se dedicar cada vez mais aos projetos que apresentavam essas características, como, por exemplo, o livro iconográfico. Em matéria publicada na revista alemã Novum Gebrauchsgraphik, de 1988, Felipe Taborda diz que Victor Burton tem uma sensibilidade especial para os projetos de livros em que há uma relação entre texto e imagem. "Ele quase pode ser chamado de monstro do design editorial, uma vez que ele não cria simplesmente a capa do livro, mas se envolve com cada página dele. O resultado é sempre excelente" (p. 7). E conclui afirmando que sua dedicação ao projeto gráfico desses livros tem feito com que ele fique conhecido como um dos mais especializados e meticulosos artistas do Brasil.

Ao se dedicar a esses livros, Victor passou a assumir um estilo gráfico próprio trazendo inovações na estética do livro brasileiro que foram de grande impacto social na medida em que seu estilo criou escola e diversos seguidores. Ana Luisa Escorel (2004), ressalta afirmando que "seu estilo requintado e extremamente pessoal atingiu 
tal sucesso junto ao público, aos editores e aos autores de texto que começaram a brotar seguidores fascinados por sua inteligência gráfica" (p.95).

Desta forma, o objetivo deste artigo é apresentar a trajetória de Victor Burton no mercado editorial brasileiro de forma a auxiliar na preservação e na construção da memória do design editorial brasileiro, além de identificar os elementos característicos do seu estilo que nos permite identificar a autoria do seu projeto gráfico. Para isso, utilizamos como metodologia as técnicas da história oral que questiona a tradição historiográfica centrada em documentos oficiais. "Sem dúvida, a história oral hoje é parte inerente dos debates sobre tendências da história contemporânea" (BOM MEIHY, 1996, p.10). Centrada na figura do entrevistador, do entrevistado e do aparato tecnológico para gravação, a história oral "é sempre uma história do tempo presente e também conhecida por história viva" (idem, p.13).

\section{A CHEGADA DE VICTOR BURTON NO MERCADO EDITORIAL BRASILEIRO}

Ao idealizar o projeto da Confraria dos Amigos do Livro, o objetivo de Carlos Lacerda era ter um segmento dentro da Nova Fronteira especializada em editar livros de arte, baseado no modelo da Sociedade dos Cem Bibliófilos, fundada por Raymundo Ottoni de Castro Maya. A expectativa de Lacerda ao convidar Victor Burton, na época com 21 anos de idade, era que o jovem designer trouxesse o know how de Franco Maria Ricci, além de haver a intenção de fazer algumas coedições com a editora italiana, o que de fato ocorreu. Porém, com a morte de Lacerda alguns meses depois, em maio de 1977, a recém inaugurada Confraria dos Amigos do Livro chega ao fim após ter lançado poucos livros, alguns deles independentes e outros em coedição com a editora italiana.

Os filhos de Lacerda, Sérgio e Sebastião, assumiram o comando da Nova Fronteira e convidaram Victor para trabalhar nesta editora com a qual Victor Burton assinou um contrato de exclusividade mútua em que ambos se comprometiam a prestar serviços, única e exclusivamente, entre si.

A chegada de Victor Burton ao mercado editorial brasileiro se deu em um momento muito favorável para o desenvolvimento do seu trabalho, uma vez que "não havia mais o inovadorismo das editoras José Olympio e Civilização Brasileira (...). Já havia passado o apogeu dos antigos capistas e tampouco surgira a nova leva de designers que atualmente estão no mercado editorial" (PERROTA, 2006, p.33).

Quando Victor começou a atuar no mercado editorial brasileiro, em 1977, as principais referências do design editorial eram as capas de Eugênio Hirsch e de Marius Lauritzen Bern desenvolvidas para a editora Civilização Brasileira, sob o comando de Ênio da Silveira no final dos anos 1950. Porém, o apogeu desses designers já havia passado e não havia mais nenhuma novidade no meio editorial. Nessa época, muitas capas ainda seguiam as diretrizes do modernismo rejeitando o uso explícito do ornamento, visto ainda como um elemento supérfluo, passível de ser retirado sem comprometer a composição. Ao contrário do que geralmente se fazia nesse período, Victor fez questão de usar tipografias das mais variadas possíveis indo contra um certo absolutismo modernista da época, como relatou em entrevista.

Eu fazia simplesmente aquilo que eu via e que eu queria recuperar dos livros de antes, dos livros mais antigos [se referindo aos livros presentes na biblioteca da família]. Isso 
pode ter sido novo numa certa época, embora fosse um olhar para trás em relação ao que se fazia no Brasil certamente era uma coisa pelo menos diferente (BURTON, 2012).

Em 1983, Victor Burton foi convidado pelo professor Arisio Rabin da Escola Superior de Desenho Industrial da Universidade do Estado do Rio de Janeiro (ESDIUERJ), para realizar uma exposição dos seus trabalhos, com duração de 21 dias, na própria ESDI. De acordo com Burton (2012), o fato de muitos professores terem criticado suas escolhas tipográficas ao não ter utilizado fontes como a Helvetica ou a Futura nos seus trabalhos, ou seja, uma fonte "decente", demonstrou que o design editorial brasileiro ainda seguia algumas diretrizes modernistas. Na época, seus trabalhos geraram um certo incômodo e uma reação anti-modernista de se querer "enfeitar" o trabalho gráfico.

Porém, nem todos concordavam com esta opinião sobre o trabalho de Victor Burton, como é o caso de Rafael Cardoso (2008) que acredita que o trabalho de Burton ajudou a redefinir o padrão do mercado editorial brasileiro na década de 1980 . Nesse período, o design, com os avanços da tecnologia, foi se libertando dos padrões rígidos estabelecidos pelas diretrizes modernistas e soluções diferenciadas como inovação e pluralismo marcaram o design gráfico brasileiro nos anos 1980.

Aos poucos, essa prática tornou-se cada vez mais comum, sendo marcante na obra de Victor Burton, cujas capas de livro impactaram fortemente o mercado editorial no exato momento em que o país saía da camisa-de-força da ditadura militar. Diversos profissionais que despontaram nesse período foram buscar nas questões ligadas à cultura e à identidade o mote para explorar uma linguagem gráfica mais autoral e arrojada (CARDOSO, 2008, p.240).

O próprio designer Victor Burton fez uma análise do seu trabalho naquele período e destacou que:

eu ficava brigando muito com um certo despotismo do modernismo da época, que não era só tipográfico, tinha a questão do grid, eram livros muito duros, pelo menos eu via dessa forma. Eu fazia questão de usar tipografias das mais variadas possíveis e tinha essa reação anti-modernista de querer enfeitar o trabalho gráfico. Não é que não se fizesse isso no Brasil, mas tinha uma tendência muito mais seca, mais áspera (BURTON, 2012).

\subsection{0 fim da exclusividade com a Nova Fronteira}

Em 1986, após vencer seu primeiro prêmio Jabuti de melhor capa, com o livro $A$ Floresta da Tijuca e a cidade do Rio de Janeiro pela editora Nova Fronteira, Victor foi convidado por Luiz Schwarcz para trabalhar na Companhia das Letras. Ao romper o contrato de exclusividade mútua com a Nova Fronteira, Victor Burton passou a desenvolver trabalhos para diversas editoras se tornando um referencial para editores e designers. A partir desse momento, Victor passa a assumir cada vez mais o projeto gráfico do livro brasileiro imprimindo sua marca no mercado editorial brasileiro. João de Souza Leite (2005), reforça dizendo que "progressivamente, ao assumir o projeto 
integral de livros de maior porte e complexidade, sua obra conquistou outro estatuto, o de pautar o parâmetro do livro ilustrado brasileiro" (p.12).

A Companhia das Letras "acabou se tornando referência para o sistema editorial brasileiro pela qualidade técnica e pelo valor cultural atribuído a seus livros" (Koracakis, 2010, p.289). Em matéria publicada no jornal O Estado de S. Paulo (2011), Schwarcz comenta que não havia nada de original no modelo adotado pela Companhia das Letras, ela apenas reuniu em um só modelo o que se fazia nas editoras Nova Fronteira, Record e Zahar, suas principais concorrentes, além de aproveitar as experiência adquiridas na Brasiliense.

Nova Fronteira, Record e Zahar tiveram influência no modelo da Companhia. A Nova Fronteira estava no apogeu, reeditando clássicos, Virgílio, Thomas Mann. Ela tinha o Victor Burton como diretor artístico; as editoras começavam a se preocupar com o visual dos livros. Você olhava para um livro e identificava imediatamente o visual da Nova Fronteira. Isso foi um exemplo incrível. A Record era uma editora que ousava mercadologicamente. E me aproximei da Zahar em 1983. Foi paixão mútua, Jorge Zahar virou um pai para mim (SCHWARCZ, 2011).

Ao romper a exclusividade com a Nova Fronteira, Victor Burton passou a trabalhar para diversas editoras e a se dedicar cada vez mais ao projeto gráfico do livro, sobretudo aqueles que apresentam uma maior relação entre texto e imagem, como os livros iconográficos. O livro é um artefato de múltipla autoria, e quanto maior a participação do designer na elaboração do projeto gráfico, maior será o grau de interferência na relação do leitor com o texto. "A práxis do design gráfico, portanto, revela um duplo caráter: o de mediação de um texto verbal, associado à noção de transparência; e o de coautoria, uma vez que as opções gráficas estabelecidas pela atividade trazem um sentido próprio que influi no leitor" (GRUSZYNSKI, 2008, p.13).

\section{O LIVRO ICONOGRÁFICO DE VICTOR BURTON}

O estilo de Victor Burton se manifesta com maior clareza nos livros em que há uma maior interferência na diagramação do miolo, em que o projeto gráfico é mais detalhado, basicamente nos livros que apresentam uma maior relação entre texto e imagem. Classificamos esses livros como pertencentes à categoria editorial livro iconográfico.

A publicação dos livros desta natureza no Brasil se tornou mais frequente a partir do momento em que empresas privadas começaram a financiar os gastos do projeto. Cacilda Teixeira da Costa (2000) data o surgimento desta categoria de livro, realizado com patrocínio de empresas, a partir da década de 1960 tendo se intensificado nos anos 1970 devido ao período de prosperidade econômica do chamado "milagre econômico". Em um período de forte censura a atividades culturais como música, cinema, teatro e literatura, os livros de arte não sofreram com as imposições da ditadura militar, o que incentivou ainda mais as edições de patrocínio.

A criação de leis de incentivo no final dos anos 1980 contribuíram para o aumento da produção de livros de valor artístico no Brasil. A Lei no 7.505, conhecida como Lei Sarney, foi promulgada em 1986 dispondo sobre os benefícios fiscais na área do imposto de renda concedidos a operações de caráter cultural ou artístico como, por exemplo, "editar obras relativas às ciências humanas, às letras, às artes e outras de 
cunho cultural". Fica estabelecido que as empresas que apoiassem projetos culturais poderiam se beneficiar de dedução de imposto de renda: "até 100\% (cem por cento) do valor das doações; até $80 \%$ (oitenta por cento) do valor do patrocínio; até $50 \%$ (cinquenta por cento) do valor do investimento" (BRASIL, 1986).

Como bem observou Sandra Reimão (2004), o livro foi o primeiro produto cultural a ser industrializado. A lei de incentivo "constituiu um estímulo à atividade editorial, incentivou a publicação de numerosos livros e, principalmente, ocasionou o surgimento de número expressivo de patrocinadores, que perceberam as vantagens do marketing cultural" (COSTA, 2000, p. 18). Ao financiar projetos culturais, como edições de luxo, os empresários conseguem abatimento de diferentes tipos de tributo. Com isso, "o financiador, na verdade, é a sociedade brasileira, que renuncia a essa arrecadação cujo montante tem crescido expressivamente" (COSTA, 2000, p. 20).

Após a Lei Sarney ser suspensa, em 1990, foi instituído o Programa Nacional de Apoio à Cultura - o Pronac -, através da Lei Federal de Incentivo à Cultura (Lei $\mathrm{n}^{\circ}$ 8.313/1991), conhecida como Lei Rouanet. Visando incentivar a produção cultural no país, estabeleceu que as doações e os patrocínios na produção cultural atenderão exclusivamente aos seguintes segmentos:

a) artes cênicas; b) livros de valor artístico, literário ou humanístico; c) música erudita ou instrumental; d) exposições de artes visuais; e) doações de acervos para bibliotecas públicas, museus, arquivos públicos e cinematecas, bem como treinamento de pessoal e aquisição de equipamentos para a manutenção desses acervos; f) produção de obras cinematográficas e videofonográficas de curta e média metragem e preservação e difusão do acervo audiovisual; g) preservação do patrimônio cultural material e imaterial; e h) construção e manutenção de salas de cinema e teatro, que poderão funcionar também como centros culturais comunitários, em Municípios com menos de 100.000 (cem mil) habitantes (BRASIL, 1991, destaque dos autores).

Com as leis de incentivo, os livros patrocinados ganharam destaque na indústria editorial. Atualmente, além da Lei Rouanet, de âmbito federal, existem outras leis de âmbito estadual e municipal em que grandes empresas investem em projetos culturais em prol de abatimentos de diferentes tributos e benefícios fiscais.

As leis de âmbito federal se aplicam por meio deduções sobre o imposto de renda devido. As leis estaduais e municipais se aplicam por meio de deduções do ICMS e por meio de deduções do ISS ou IPTU devidos, respectivamente. De acordo com a Medida Provisória $n^{\circ} 1.739$, de 1999, os investimentos em livros de valor artístico, literário ou humanístico têm $100 \%$ de dedução, além do patrocinador ainda ter direito a $25 \%$ do produto cultural patrocinado, ou seja $25 \%$ do número de exemplares produzidos (COSTA, 2000, p. 23).

Os livros de Burton se enquadram nas características estabelecidas pelo Pronac. São livros de valor artístico, literário ou humanístico com imagens pré-existentes, geralmente oriundas de algum acervo ou coleção. Araújo (2008) apresenta a diferença entre o ilustrador e o iconógrafo: "na atualidade, porém, entende-se que o ilustrador faz, executa, as imagens para o livro (...), enquanto o iconógrafo estuda e seleciona as ilustrações adequadas ao livro, provindas das mais diversas fontes, e.g., pintura, escultura, glíptica, cartografia, gravura, fotografia" (p. 444). Desta forma, classificamos os livros de Burton como livros iconográficos. 
O termo iconografia é definido no Dicionário de Artes Gráficas, de Frederico Porta, e pelo Dicionário Aurélio da Língua Portuguesa, respectivamente como:

1. Conhecimento e descrição das imagens, retratos, representações alegóricas, de bustos, monumentos, etc. 2 . Coleção ou conjunto de retratos referentes a uma dada pessoa.

1. Arte de representar por meio da imagem. 2. Conhecimento e descrição de imagens (gravuras, fotografias, etc.). 3. Documentação visual que constitui ou completa obra de referência e/ou de caráter biográfico, histórico, geográfico, etc.

\subsection{O estilo de Victor Burton}

Ao analisar 50 livros deste designer, percebemos que os principais elementos que vão caracterizar seu estilo:

1) o uso de imagens documentais - sejam elas objetos tridimensionais, pinturas, fotografias etc. que fazem parte da iconografia abordada na obra - como elementos decorativos (fig. 1);

2) chamar atenção para uma determinada imagem da iconografia abordada na obra através da ampliação e/ou do recorte (fig. 2);

3) o uso de ornamentos e de elementos decorativos tipográficos, como florões, vinhetas e capitulares (fig. 3);

4) a utilização predominante de grandes famílias tipográficas serifadas, em todas as suas variações: itálico, versalete, negrito, regular etc. (fig. 4);

5) apresentação da folha de rosto em página dupla, influência do editor francês Robert Delpire (fig. 5).

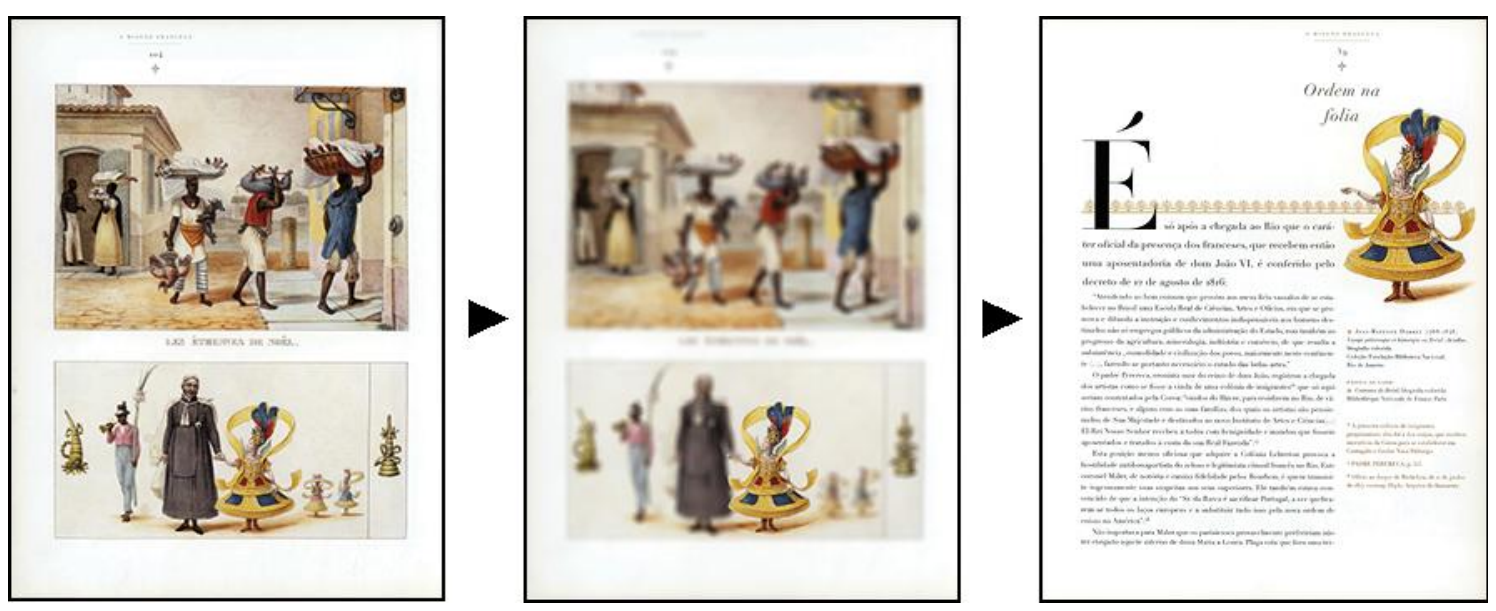

Figura 1 - exemplo de uso de imagem iconográfica como elemento decorativo no livro"A Missão Francesa" 


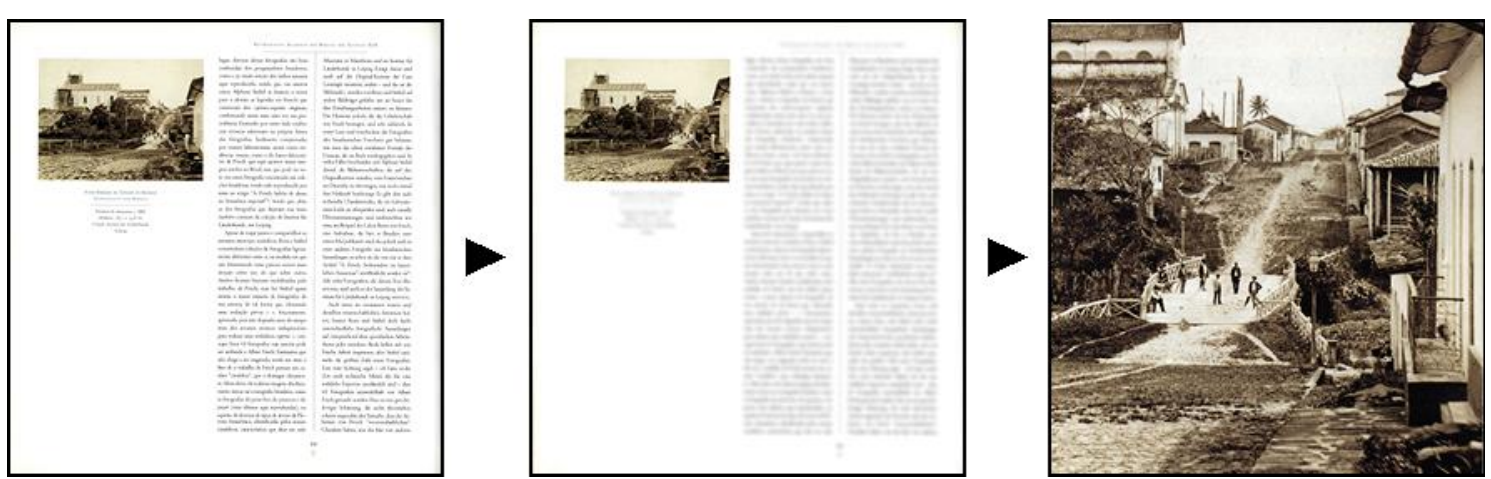

Figura 2 - exemplo de destaque de uma determinada região da imagem iconográfica no livro"Fotógrafos alemães no Brasil do século XIX"
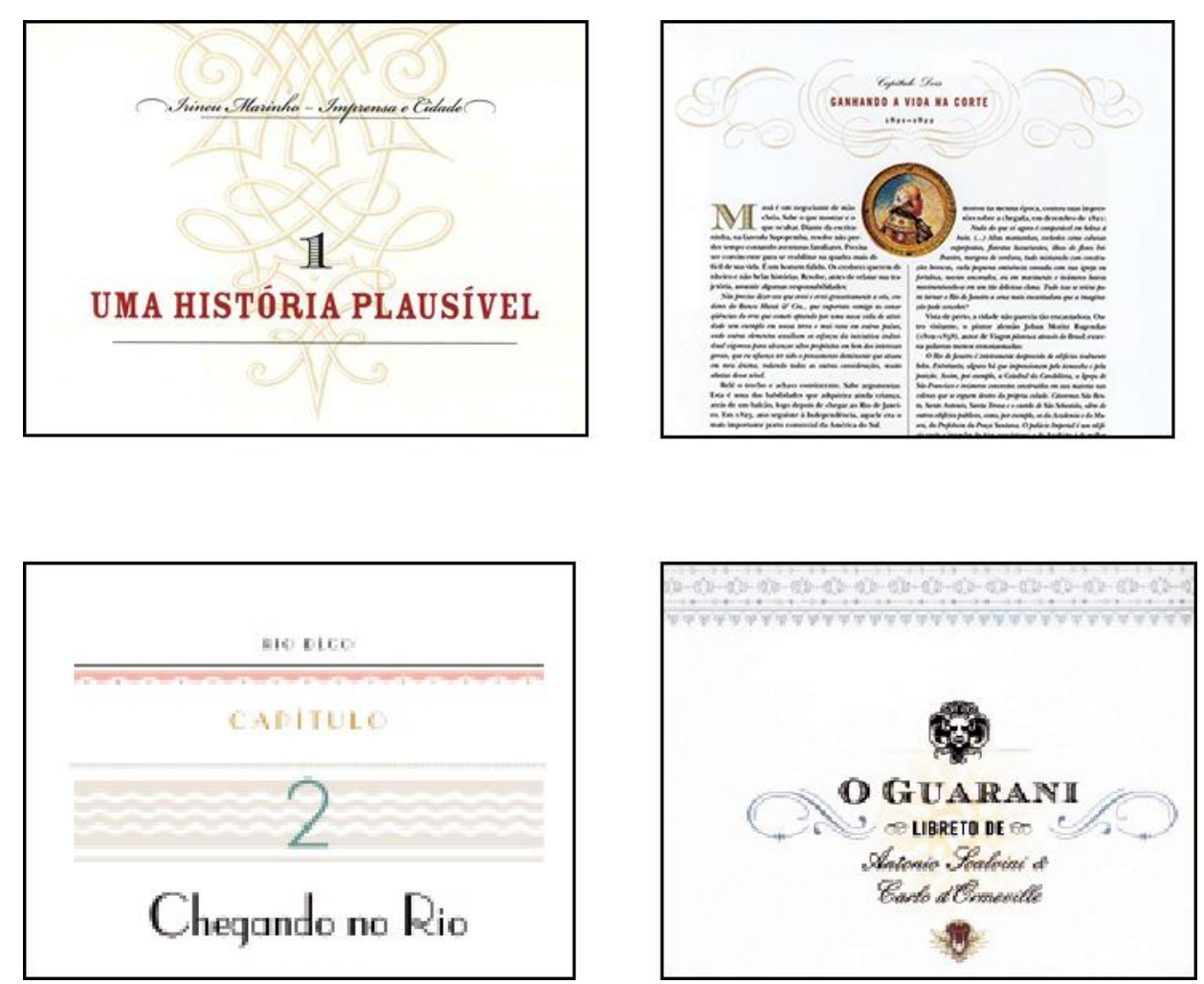

Figura 3 - exemplos do uso de ornamentos 

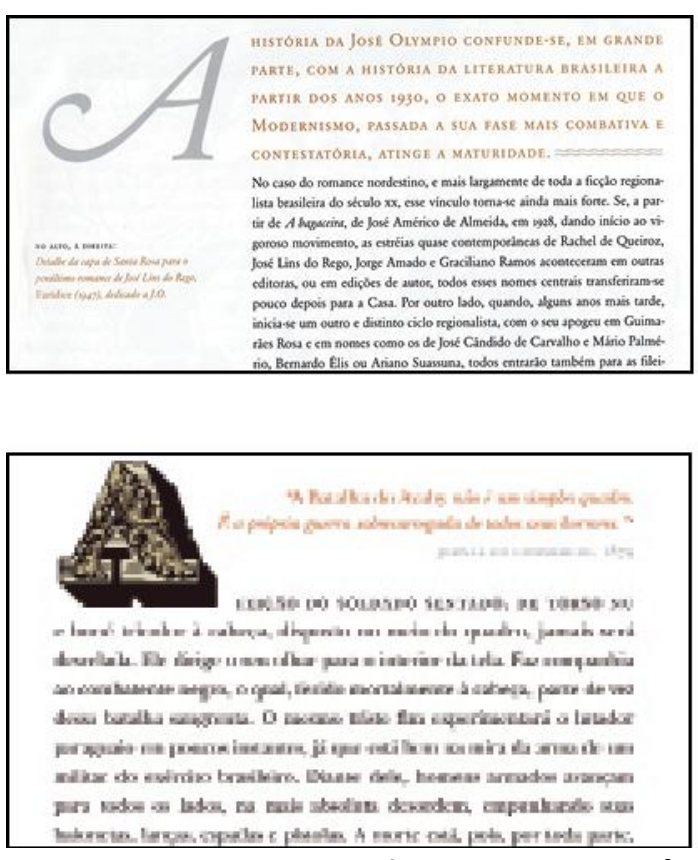

Figura 4 - exemplos de famílias tipográficas
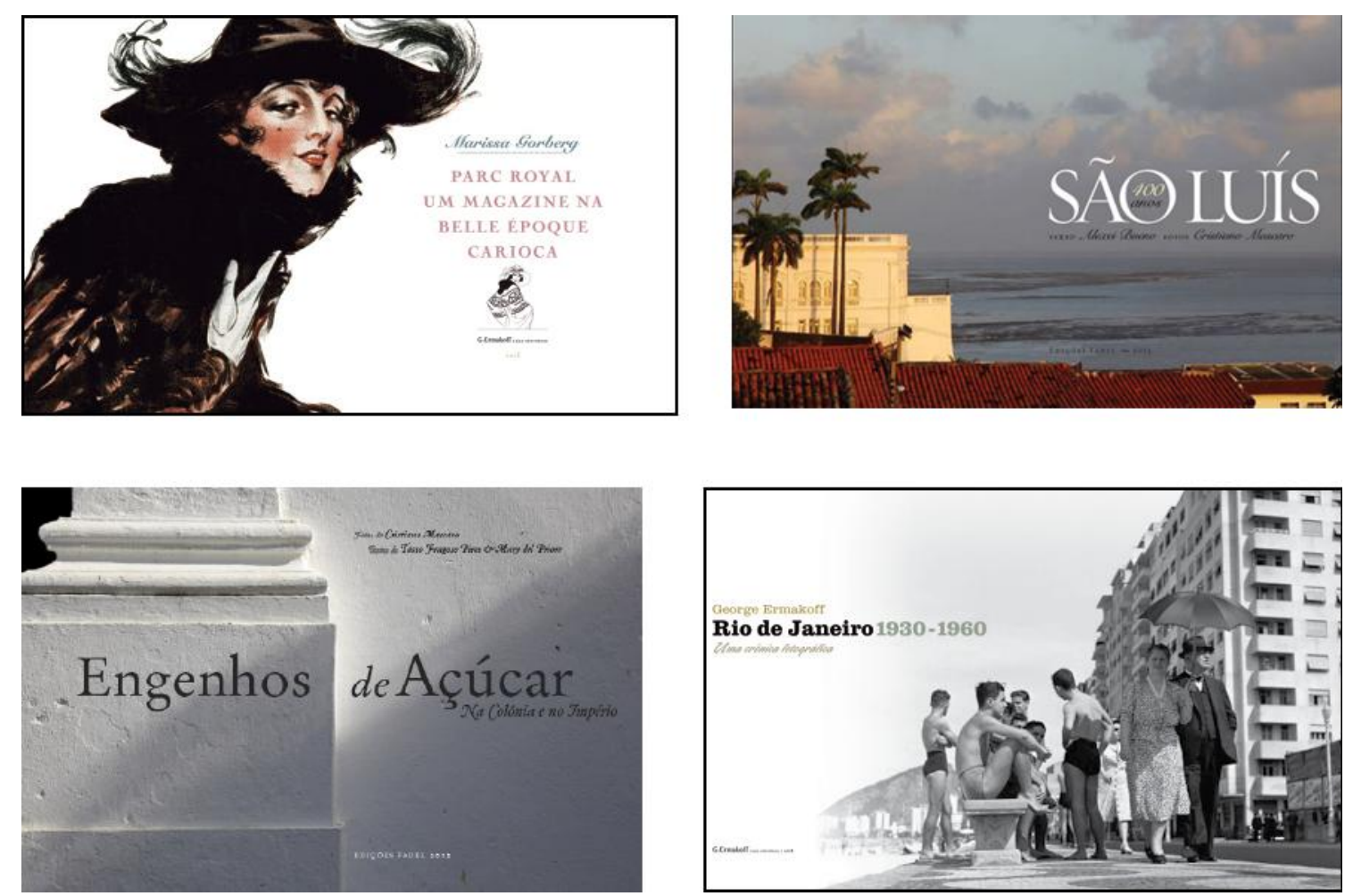

Figura 5 - exemplos de folhas de rosto em páginas dupla

Esses são os principais elementos que fazem parte do universo que caracteriza a linguagem gráfica de Victor Burton e definem seu estilo. Entretanto, esses elementos são característicos de apenas um dos estilos deste designer que também apresenta outras linguagens. Esse estilo talvez seja o que mais o identifique posto que a maior parte da sua produção envolve temas relacionados à história e à arte do século XIX. E, de acordo com Burton (2013), "quando eu faço um livro sobre o tema do século XIX eu 
procuro fazer alguma coisa que tenha a ver com isso, busco uma tipografia da época, uma vontade de recuperar alguma coisa da estética da época". Burton (2013) explica que

tudo depende do assunto, do tema. Eu talvez tenha ficado um pouco preso no século $\mathrm{XIX}$ e as pessoas ficam trazendo essa temática pra mim e eu fico um pouco preso nessa estética [...]. Eu costumo fazer uma relação historicista com a tipografia, eu gosto de trabalhar com uma espécie de arqueologia tipográfica. Você poderia fazer a mesma coisa com a tipografia com um ponto de vista gráfico completamente contemporâneo, mas eu acho mais interessante você trabalhar esse mergulho no tempo (BURTON, 2013).

Apesar de Victor Burton apresentar diferentes linguagens, neste trabalho focamos nossa análise nos livros iconográficos que, em sua maioria, apresentam temas relacionados à história e à arte do século XIX. O que nos permite identificar seu o estilo é a forma singular com a qual ele trabalha os elementos da iconografia, que como o próprio Victor destacou, se refere mais a uma metodologia de trabalho, na medida em que ele procura relacionar de alguma forma o projeto gráfico do livro com a estética da época.

\section{CONCLUSÃO}

O estilo desenvolvido por Burton é considerado por muitos autores como sendo elegante e requintado. É o caso de Ana Luisa Escorel que analisa as repercussões do seu trabalho no meio editorial: "seu estilo requintado e extremamente pessoal atingiu tal sucesso junto ao público, aos editores e aos autores de texto que começaram a brotar seguidores fascinados por sua inteligência gráfica" (ESCOREL, 2004, p.95). Já para Tschichold (2007) “o perfeito design de livro, portanto, é uma questão de tato (andamento, ritmo, toque) somente. Provém de algo raramente valorizado hoje: bom gosto" (p. 33).

Escolher uma fonte bem ajustada ao texto; projetar uma página primorosa, idealmente legível, com margens harmonicamente perfeitas, impecável espacejamento de palavras e letras; escolher corpos de tipo ritmicamente corretos para folhas de rosto e títulos, e compor as páginas em que há títulos de seção e de capítulos genuinamente belas e graciosas, no mesmo tom da página de texto - por esses meios um designer de livro pode contribuir muito para a fruição de uma valiosa obra de literatura (TSCHICHOLD, 2007, p.32).

Após a análise dos livros de Burton pudemos perceber como ele constrói uma narrativa visual que dá suporte à leitura do texto, da narrativa textual. A partir de imagens recortadas do próprio acervo iconográfico tratado no livro, Victor cria uma segunda leitura gráfica - uma trama que vai permeando todo o livro tornando a leitura textual mais leve e prazerosa. Desta forma, ele se torna um mediador no processo de comunicação o que demonstra a relação do seu trabalho com o processo de edição. Esse é um diferencial do seu trabalho e uma importante característica do seu estilo.

Ao desenvolver uma nova leitura icônica para o texto escrito, surge um novo questionamento: seria Victor Burton um coautor do livro iconográfico? Mas isso é uma outra história. 


\section{REFERÊNCIAS}

ARAÚJO, Emanuel. A construção do livro. Rio de Janeiro: Nova Fronteira, 2008.

BOM MEIHY, José Carlos S. Manual de história oral. São Paulo: Edições Loyola, 1996.

BRASIL. Lei no 8.313, de 23 de dezembro de 1991. Restabelece princípios da Lei $n^{\circ}$ 7.505, de 2 de julho de 1986, institui o Programa Nacional de Apoio à Cultura (Pronac) e dá outras providências. Diário Oficial [da] República Federativa do Brasil, Brasília, DF, $24 \quad$ dez. $1991 . \quad$ Disponível em <http://www.planalto.gov.br/ccivil_03/leis//8313cons.htm> Acesso em 23 de junho de 2013.

. Lei no 7.505, de 02 de julho de 1986. Dispõe sobre benefícios fiscais na área do imposto de renda concedidos a operações de caráter cultural ou artístico. Diário Oficial [da] República Federativa do Brasil, Brasília, DF, 03 jul.1986. Disponível em <http://www.planalto.gov.br/ccivil_03/leis/L7505.htm> Acesso em 23 de junho de 2013.

BURTON, Victor. Entrevista concedida à autora. Rio de Janeiro, 18 mai. 2012. . Entrevista concedida à autora. Rio de Janeiro, 25 nov. 2013.

CARDOSO, Rafael. Uma introdução à história do design. São Paulo: Edgard Blücher, 2008.

COSTA, Cacilda Teixeira da. Livros de arte no Brasil: edições patrocinadas. São Paulo: Itaú Cultural, 2000.

ESCOREL, Ana Luisa. O efeito multiplicador do design. São Paulo: Editora Senac, 2004.

GRUSZYNSKI, Ana Cláudia. Design Gráfico: do invisível ao ilegível. São Paulo: Edições Rosari, 2008.

KORACAKIS, Teodoro. Uma história em processo: a Companhia das Letras de 1986 a 2006. In: BRAGANÇA, Aníbal; ABREU, Márcia (orgs.) Impresso no Brasil: dois séculos de livros brasilieros. São Paulo, Editora Unesp, 2010.

LEITE, João de Souza. Coleção Portfolio Brasil Design Gráfico - Victor Burton. São Paulo: J. J. Carol editora, 2005.

PERROTA, Isabella. Victor Burton. Rio de Janeiro: Viana \& Mosley, 2006.

REIMÃO, Sandra. Livros e televisão: correlações. São Paulo: Ateliê Editorial, 2004. Disponível em: < http://escritoriodolivro.com.br/historias/sandra.html>. Acesso em 23 de junho de 2013. 
SCHWARCZ, Luiz. Rumo a uma nova estação editorial. Disponível em: <http://www.estadao.com.br/noticias/impresso, rumo-a-uma-nova-estacaoeditorial,751977,0.htm> Acesso em: 09 de janeiro de 2013.

TABORDA, Felipe. Victor Burton. In: Revista Novum Gebrauchsgraphik, ano 59, pp. 49, fevereiro de 1988.

TSCHICHOLD, Jan. A forma do livro: ensaios sobre tipografia e estética do livro. São Paulo: Ateliê Editorial, 2007. 